\title{
Development of a Heat Source Model for Narrow-gap Hot-wire Laser Welding*
}

\author{
Rittichai Phaonaim**, Masayuki Yamamoto**, Kenji Shinozaki***, Motomichi Yamamoto***, \\ and Kota Kadoi***
}

Three-dimensional finite element analysis with a special subroutine was carried out to obtain the temperature distribution during hot-wire laser welding with a narrow-gap joint. A moving heat source was modeled with the element rebirth technique, and laser reflection was modeled by heat flux distributed around the front of the weld pool. The model was used to reproduce the phenomenon of hot-wire laser welding with a narrow gap investigated by in-situ observation. The thermal strain for different weld shapes was then calculated to evaluate the susceptibility to solidification cracking. The simulation results were validated with experimental measurements in terms of the thermal cycle history of the molten pool, peak temperature distribution close to the fusion zone, and cross section of the weld bead. The thermal simulation was found to agree reasonably well with the experimental results and it was revealed that hot-wire laser welding is an interesting alternative process that reduces solidification cracking in a narrow-gap joint.

Key Words: Hot-wire Laser Welding, Narrow Gap, Heat Source, Solidification Cracking

\section{Introduction}

Conventional welding processes for a narrow-gap joint allow good productivity. Nevertheless, these methods, and particularly submerged arc welding, suffer from grain growth owing to high input heat energy. Subsequently, a technique requiring lower heat input energy has been developed using a hot-wire system designed to independently control the melting feed wire and the base metal. Nowadays, hot-wire gas-tungsten arc welding is employed with a narrow-gap joint in industry. However, this method is still limited in terms of the efficiency of the process and the quality of the weldment ${ }^{1-3)}$. Consequently, hot-wire laser welding with a narrow gap has been proposed by the authors ${ }^{4}$. This is a hybrid process that realizes high welding speed, high weld deposition, low deformation and a low dilution. Furthermore, the laser beam reflecting from the molten pool heats and melts the base material in front of the molten pool, thus reducing the dilution of base material (less than $10 \%$ ). However, previous studies have reported that the technique results in solidification cracking in modified $9 \mathrm{Cr} 1 \mathrm{Mo}^{5}$ ). The authors have carried out studies of predicting the occurrence of solidification cracking during laser welding ${ }^{6)}$. Solidification cracking in a

\footnotetext{
${ }^{*}$ Received: 2012.11 .26

${ }^{* *}$ Student Member, Graduate, School of Engineering, Hiroshima University

${ }^{* * *}$ Member, Graduate, School of Engineering, Hiroshima University
}

narrow-gap welded joint was quantitatively evaluated according to the intersection of material resistance as a high-temperature ductility curve and the thermal strain rate. As for thermal strain, temperature distributions are important in estimating the driving forces during welding, while a thermal-strain phenomenon is so complicated that the general equation of the heat source model cannot be applied. This study proposes a three-dimensional (3-D) finite element model with a moving heat source for hot-wire laser welding with a narrow-gap joint, and validates the model with experimental measurements. Furthermore, a recent report published by the authors indicated that the depth-to-width $(\mathrm{D} / \mathrm{W})$ ratio affects solidification cracking susceptibility ${ }^{5)}$. In particular, for $\mathrm{D} / \mathrm{W}$ ratios more than 1.2 or less than 0.6 , solidification cracking does not occur for a groove width of $3 \mathrm{~mm}$. Accordingly, the strain history during solidification was calculated to mechanically analyze the effect of the $\mathrm{D} / \mathrm{W}$ ratio on the susceptibility of solidification cracking.

\section{Experimental Procedure and Calculation Model}

\subsection{Experimental Procedure}

Modified 9Cr1Mo steel was used as a base metal. The dimensions of the sample plate were $120 \mathrm{~mm} \times 75 \mathrm{~mm} \times 21 \mathrm{~mm}$. A U-shaped groove joint with a gap width of $3 \mathrm{~mm}$ was applied. Welding conditions were set as laser output power of $3 \mathrm{~kW}$, a diameter of the defocused laser beam of $3 \mathrm{~mm}$, welding speed of $0.3 \mathrm{~m} / \mathrm{min}$, a wire diameter of $1.2 \mathrm{~mm}$, and feeding speed of 4.8 
$\mathrm{m} / \mathrm{min}$. The computational simulation was verified by comparison with the experiment in terms of the thermal history, peak temperature distribution close to the fusion zone, and the cross section of the weld bead. Temperature was measured using an optical-fiber radiation thermometer (JFE Mechanical Corporation $)^{7)}$ in the weld metal because it can acquire data during rapid cooling. Thermocouples were also set in the direction transverse to the weld.

\subsection{Finite Element Model}

The thermal distribution and mechanical strain were obtained using the finite element method (within commercial code MSC.Marc 2012) and a special subroutine program. Because of the symmetry of the sample plate along the weld centerline, one half of the sample plate was discretized with the 3-D thermo-mechanical solid elements of eight-node isoparametric hexahedral type. Finer $0.25-\mathrm{mm}$ elements in the weld metal and coarser $0.5-\mathrm{mm}$ elements near the fusion zone were used as shown in Fig. 1. The convection heat loss was defined by a heat transfer coefficient of $45 \mathrm{~W} / \mathrm{m}^{2} / \mathrm{K}$ at all plate surfaces except the symmetry plane, where an adiabatic condition was assumed. Radiation heat loss was negligible. Under a mechanically restrained condition, all nodes on the symmetry surface of a welding bead along the longitudinal direction were fixed in the direction transverse to the welding. The side edge of a work piece was constrained to prevent rotational movement.

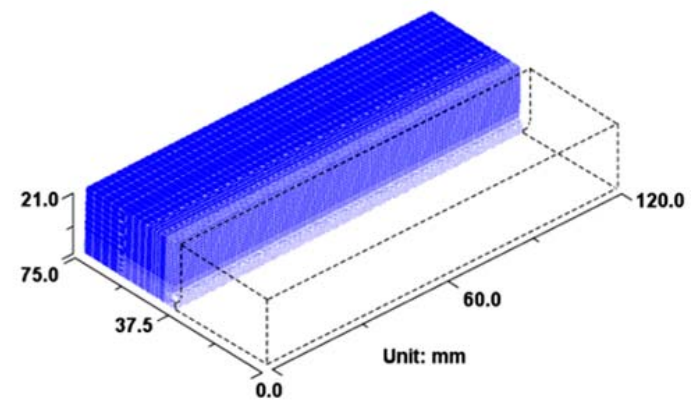

Fig. 1 Finite element model.

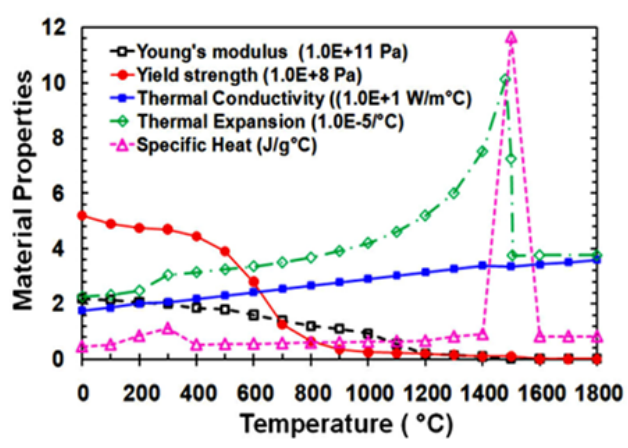

Fig. 2 Material properties against temperature.

\subsection{Material Properties}

Thermo-mechanical material properties dependent on temperature, specifically thermal conductivity, specific heat, and thermal expansion, were estimated by taking a thermodynamic approach and using commercial software JMatPro. Poisson's ratio was assumed to be 0.29 and the mass density was $7750 \mathrm{~kg} / \mathrm{m}^{3}$. Solidus and liquidus temperatures were assigned as 1440 and $1505{ }^{\circ} \mathrm{C}$ respectively. Yield strength and Young's modulus were obtained from a literature review ${ }^{8)}$ (Fig. 2).

\subsection{Heat Source Model}

The complex phenomenon of the molten pool behavior in hot-wire in laser welding with a narrow gap has been observed using a high-speed camera ${ }^{4}$. A heat source model consistent with the observed phenomenon is illustrated in Fig. 3. The shape of the weld pool was generated using rebirth elements with initial uniform temperature (Q1) that was almost equal to the wire's melting point $\left(1436{ }^{\circ} \mathrm{C}\right)$. The process is repeated in each time-step increment to provide the weld deposition from the fed hot wire. The thermal energy from the laser beam (Q2) with a heat absorbance coefficient of 0.15 was then distributed on the deposited elements to raise the temperature slightly above the melting point. Furthermore, the energy of the laser beam (Q3) reflected from the molten pool surface with a heat absorbance coefficient of 0.35 is transmitted to the front of the molten pool and a sidewall of the groove via the heat flux density applied around the weld pool. The ratio of heat energy between reflected laser radiation and direct laser radiation was assigned to be approximately 0.3 .

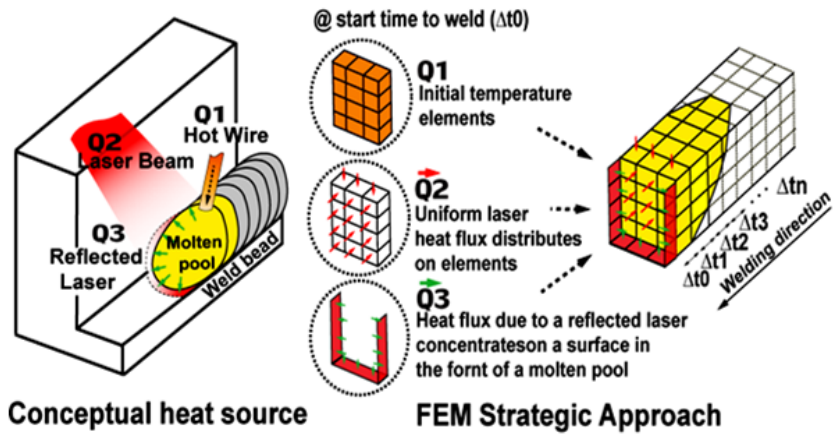

Fig. 3 Schematic illustration of the heat source.

\subsection{Thermo-mechanical Strain Analysis}

Following thermal analysis, the moving heat source in hot-wire laser welding with a narrow gap was applied to three different weld shapes that correspond to shapes in an earlier study ${ }^{3)}$ on susceptibility to solidification cracking; the weld shapes had been used to investigate the plastic strain rate during solidification. The $\mathrm{D} / \mathrm{W}$ ratios of the weld shapes were $0.5,0.9$, and 1.5 and were obtained by adjusting the wire feeding speed. In the present simulation, a special subroutine program was developed to reset the mechanical strain within molten pool elements when the 
temperature of the welding pool exceeded the melting point. The strain then recovered after starting solidification behind $50 \%$ solid fraction which is designated as $1495^{\circ} \mathrm{C}$.

\section{Results and Discussion}

Figure $4 \mathrm{a}$ shows the temperature distribution and the molten pool shape as the heat source moves throughout welding. It is seen that there is greater fusion near the front of the molten pool. This is due to the heat flux of the reflected laser light inducing melting around the pool front and the side wall of the groove.

To verify the suitability and validity of the simulation, the results were compared with experimental results in terms of the peak temperature distribution and thermal history. In addition, the cross-section of the fusion zone was considered in confirming the accuracy of the simulation as presented in Fig. 4 b). In terms of the weld cross-section, it was found that the computed fusion zone with temperature exceeding the melting point $\left(1505{ }^{\circ} \mathrm{C}\right)$ satisfactorily matched the experimental weld pool shape.

Figure 5 shows the maximum temperature distribution in the direction transverse to the welding. There were three measurement points spaced at intervals of $1 \mathrm{~mm}$, for which a regression line was estimated. The figure shows that the computational simulation and experimental results agree well.

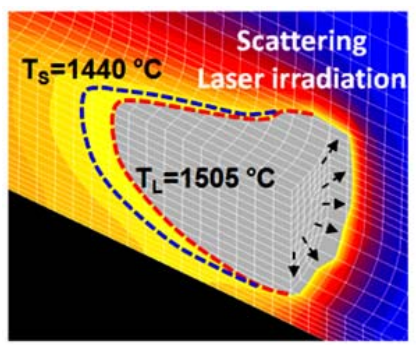

a) Weld pool shape

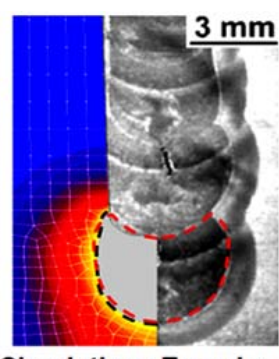

Simulation: Experiment b) Cross section
Fig. 4 Temperature distribution and cross sectional view.

To verify the calculated temperature distribution, the temperature history obtained from thermal analysis was compared with measurements made using the optical-fiber radiation thermometer in the fusion zone. Figure 6 shows that the thermal cycle obtained from simulation coincides with the measurement line.

To illustrate the effect of the weld shape on the strain rate during solidification, Fig. 7 shows the simulated weld pool shapes compared with experimental observations. Note that the hot-wire laser process was able to control the amount of penetration of a side wall. In the case of a $\mathrm{D} / \mathrm{W}$ ratio of 1.5 , there was not only a very low penetration but also a high deposition rate. In contrast, $\mathrm{D} / \mathrm{W}$ ratios of 0.5 and 0.9 resulted in more fusion. Figure 8 shows the cross section where the highest strain rate initiated for each
D/W ratio. It was found that such critical points occurred near the middle of the weld bead and within the mushy zone.

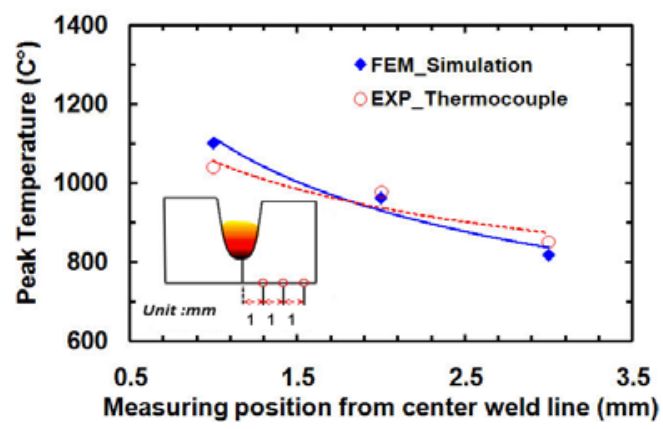

Fig. 5 Peak temperature distribution.

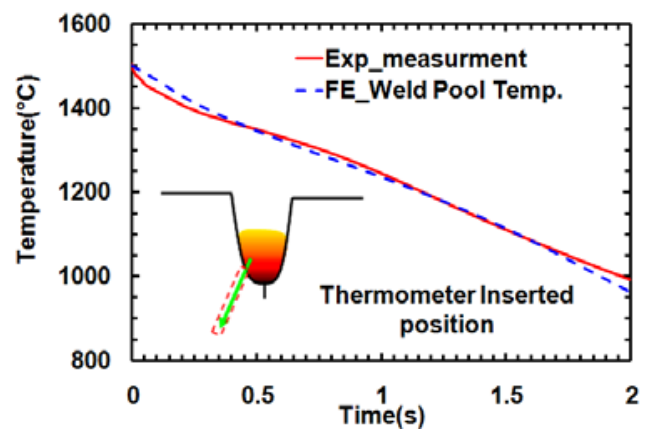

Fig. 6 Temperature history.

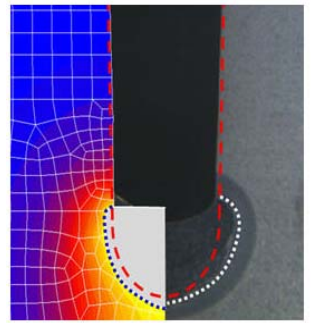

a) $\mathrm{D} / \mathrm{W}=0.5$

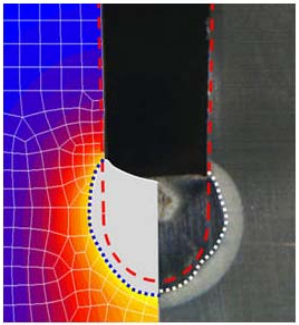

b) $\mathrm{D} / \mathrm{W}=0.9$

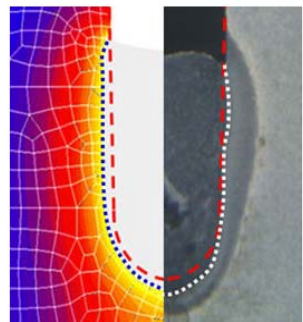

c) $\mathrm{D} / \mathrm{W}=1.5$

Fig. 7 Weld shapes.

It is important to consider the strain history of the mushy zone in each critical zone. The computational results in Fig. 9 reveal that a $\mathrm{D} / \mathrm{W}$ ratio of 0.9 provides the highest strain rate, followed by $\mathrm{D} / \mathrm{W}$ ratios of 0.5 and 1.5 . 
a)

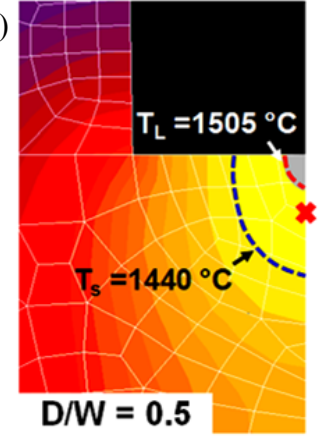

$1 \mathrm{~mm}$

$\mathrm{D} / \mathrm{W}=1.5$

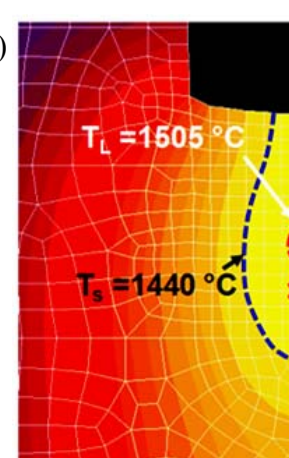

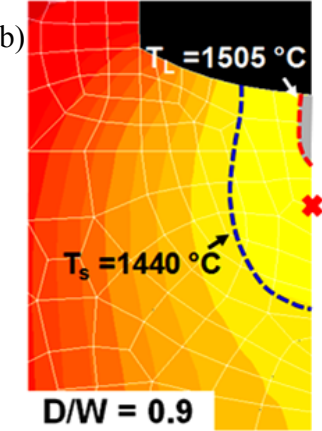

$1 \mathrm{~mm}$
* Max. strain rate location

\section{$1 \mathrm{~mm}$}

Fig. 8 Position of the highest strain rate.

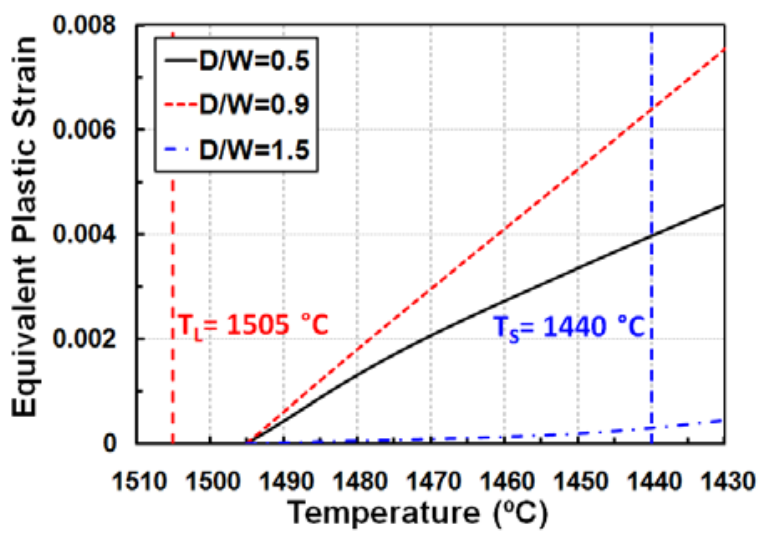

Fig. 9 Strain history curves.

It is considered that solidification cracking usually occurs for traditional welding of a narrow gap with a $\mathrm{D} / \mathrm{W}$ ratio higher than $1.3^{9)}$, while the authors' report as mentioned showed that hot-wire laser welding was suitable for $\mathrm{D} / \mathrm{W}$ ratios exceeding 1.2 without solidification cracking. In the present study, simulation revealed a low risk of solidification cracking, from a mechanical view, at high $\mathrm{D} / \mathrm{W}$ ratios such as 1.5 in hot-wire laser welding, which would be difficult to achieve using a general heat source in conventional welding.

\section{Conclusions}

A heat source model was developed to analyze the temperature distribution during hot-wire laser welding with a narrow gap. Thermo-mechanical analysis was carried out employing the 3-D finite element method and a special user subroutine. It was found that the simulation result agrees reasonably well with experimental results. Furthermore, it was found that the extraordinary heat source employed in hot-wire laser welding reduces susceptibility to solidification cracking.

\section{References}

1) U. Reisgen, S. Olschok , S. Jakobs, M. Schleser, O. Mokrov, E. Rossiter: Laser Beam Submerged Arc Hybrid Welding, J. Physics Procedia, 39(2012), 75-83.

2) S. Iwata, M. Murayama, Y. Kojima: Application of narrow gap welding process with high speed rotating arc to box column joints of heavy thick plates, JFE technical report, 14(2009), 16-21.

3) N. Gou, J. Zhang, Y. Han, L. Zang, X. Yuan: Effects of welding parameters on metal transfer process in rotating are narrow gap horizontal GMAW, Trans. of JWRI, Special issue on WSE, (2011), 5-7.

4) R. Phaoniam, K. Shinozaki, M. Yamamoto, K. Kadoi, S. Tsuchiya, A. Nishijima : Development of high efficient hot wire-laser hybrid process for narrow gap welding -Welding phenomena and its adequate condition, $65^{\text {th }}$ IIW Annual Assembly, Doc.IV-1095-12 /XII-2093-12/212-12-1253-12.

5) K. Shinozaki, A. Nishijima, M. Yamamoto, K. Kadoi, R. Phaoniam, M. Yamamoto, T. Okagaito: Behavior and prevention of lack fusion and solidification cracking of modified 9Cr1Mo steel during hot wire laser welding with a narrow gap, Proceedings of the $77^{\text {th }}$ laser materials processing, (2012), 21-26. (in Japanese)

6) K. Shinozaki, M. Yamamoto, A. Kawasaki, T. Tamura, Peng Wen: Development of evaluation method for solidification cracking susceptibility of inconel600/sus347 dissimilar laser weld metal by in-situ observation, J. Mater. Sci. Forum, 580-582(2008), 49-52.

7) Y. Ueno, S. Ishii, Z. Yamanaka: Measurement of weld metal temperature with an immersion-type optical-fiber radiation thermometer without correcting emissivity, J. Japanese Welding Society, 81(7) (2012), 17-21. (in Japanese)

8) D. Deng, H. Murakawa: Prediction of welding residual stress in multi-pass butt-welded modified $9 \mathrm{Cr}-1 \mathrm{Mo}$ steel pipe considering phase transformation effect, J. Computational Mater. Sci., 37 (2006), 209-219.

9) M. Shibahara, S. Itoh, W. Liang, H. Murakawa: finite element simulation of pear-shaped bead cracking in narrow gap welding, Proceedings of The $13^{\text {th }}$ International Offshore and Polar Engineering Conference, (2003),135-140. 